\section{SAT0232 PERCEPTION OF THE DISEASE IN PATIENTS WITH EARLY SYSTEMIC LUPUS ERYTHEMATOSUS}

M. Garabajiu', L. Mazur-Nicorici' ${ }^{1}$, T. Rotaru² ${ }^{2}$, V. Salaru' ${ }^{1}$, S. B. Victoria ${ }^{1}$, S. Vetrila ${ }^{1}$, N. Loghin-Oprea ${ }^{1}$, M. Mazur ${ }^{1} .{ }^{1}$ State University of Medicine and Pharmacy “Nicolae Testemitanu", Chisinau, Moldova, Republic of; ${ }^{2}$ PSMI Institute of Cardiology, Chisinau, Moldova, Republic of

Background: Systemic lupus erythematosus is an autoimmune disease with a major impact on patient's quality of life.

Objectives: To evaluate patient's attitude toward early disease and factors that influence it.

Methods: Performed case-control study included SLE patients that fulfilled SLICC, 2012 classification criteria. The research included two groups of patients: early SLE $-1^{\text {st }}$ group (disease duration $\leq 24$ months) and non-early SLE $-2^{\text {nd }}$ group control (disease duration $>24$ months). The pattern of the disease activity was assessed by patient global assessment (PGA), Systemic Lupus Erythematosus Disease Activity Index 2000 (SLEDAI-2K) and Systemic Lupus Activity Measure (SLAM), for SLE activity, SLICC/ACR Damage Index (DI) for disease irreversible changes and SF-8 for the Quality of Life (QoL)

Results: A total of 101 SLE patients with 34 in the $1^{\text {st }}$ group (early SLE) and 67 in the $2^{\text {nd }}$ group (non-early SLE) was analyzed. The disease activity showed high disease activity in both groups by SLEDAI $(7,02 \pm 4,16$ and $6,26 \pm 4,43$ points, $p>0,05)$ and SLAM $(7,47 \pm 4,40$ and $7,31 \pm 4,10$ points, $p>0,05)$ such as $(46,97 \pm 19,39$ vs $47,98 \pm 22,41$ points). The QoL was appreciated as low, by both components (mental and physical), in groups. The damage index was higher in the 2nd group $(0,23 \pm 0,43$ and $1,07 \pm 1,29, p<0,001)$, which can be explained by the development of irreversible changes with the increase of disease duration.

The PGA in early SLE was influenced by subjective symptoms contained in SLAM index $(r=0,48, p<0,05)$, such as fatigue and depression, and the level of the quality of life $(r=0,65, p<0,001)$. Meantime, $P G A$ in patients with longer disease duration ( $>2$ years), was influenced by the presence of organ damage by SLICC/ACR DI $(0,23, p<0,05)$ and objective findings of the disease activity contained in SLEDAI $(r=0,33, p<0,005)$ and $\operatorname{SLAM}(0,44$, $\mathrm{p}<0,001)$.

Conclusion: The disease recognition in patients with early SLE was determined by subjective and psycho-emotional signs, while in patients with longer disease duration it was influenced by organ damage and complications.

References: no references

Disclosure of Interests: None declared

DOI: 10.1136/annrheumdis-2020-eular.5406

\section{SAT0233 CHARACTERISTICS OF PRIMARY SJÖGREN'S SYNDROME INCLUDING ULTRASOUND FINDINGS OF THE SALIVARY GLANDS, ESSDAI AND ESSPRI}

N. S. Schmidt ${ }^{1}$, A. Voss ${ }^{1}$, S. A. Just ${ }^{1}$, H. M. Lindegaard ${ }^{1} .{ }^{1}$ Odense University Hospital, Rheumatology, Odense, Denmark

Background: Studies have shown that salivary gland ultrasonography (SGUS) may have a potential value in the diagnosis of Sjogren's Syndrome (SS).

Knowledge of the association between ultrasonography findings, disease activity and damage, serologic markers and patient report outcome is limited.

Objectives: To investigate whether the results of SGUS are associated with disease manifestations and damage measured by doctor-reported activity score index (ESSDAI) and serologic markers. Furthermore to investigate the contribution of patient reported outcome measure (ESSPRI) in disease monitoring

Methods: Patients registered at Odense University Hospital with the diagnosis primary SS were included in a Danish cohort. The patients were characterized using the ESSDAI, ESSPRI, serologic markers and SGUS-findings in submandibular and parotid glands. Schirmer's test and salivary test were performed for measurement of tear and salivary production.

SGUS was performed using a linear transducer, Siemens (ACUSON Sequoia Ultrasound System) on the two parotid and two submandibular glands. SGUS images was scored according to the OMERACT SS severity scoring system from 0 to 3 , where 2 is moderate and 3 severe(1). A reliability study was performed in advance of the present study.

Spearman's $r$ correlation coefficient was used to assess correlation between scores.

Results: The cohort consisted of 48 Caucasian patients diagnosed with primary SS. Details on patient characteristics are shown in table 1.
Table 1.

\begin{tabular}{|c|c|}
\hline \multicolumn{2}{|l|}{ Sex, n (\%) } \\
\hline Women & $46(95.8)$ \\
\hline Age, mean $(95 \% \mathrm{Cl})$ & $60(57-62)$ \\
\hline \multicolumn{2}{|l|}{ Smoking, $\mathrm{n}(\%)$} \\
\hline Smoker & $1(2.1)$ \\
\hline \multicolumn{2}{|l|}{ BMI, n (\%) } \\
\hline$<18.5$ & $5(10.4)$ \\
\hline $18.5-24.9$ & $20(41.7)$ \\
\hline $25.0-29.9$ & $12(25.0)$ \\
\hline $30.0-34.9$ & $10(20.8)$ \\
\hline$>35.0$ & $1(2.1)$ \\
\hline \multicolumn{2}{|l|}{ Serologic markers, n (\%) } \\
\hline SSa positive & $33(68.8)$ \\
\hline SSb positive & $22(45.8)$ \\
\hline ANA positive & 38 (79.2) \\
\hline Cryoglobulin positive & $9(18.8)$ \\
\hline \multicolumn{2}{|l|}{ ESSPRI 0-10, mean $(95 \% \mathrm{Cl})$} \\
\hline Dryness & $7.3(6.7-7.9)$ \\
\hline Fatigue & $7.1(6.4-7.7)$ \\
\hline Pain & $5.9(5.1-6.7)$ \\
\hline \multicolumn{2}{|l|}{ SGUS, $n(\%)$} \\
\hline Score 0 & $6(12.5)$ \\
\hline Score 1 & $15(31.3)$ \\
\hline Score 2 & $13(27.1)$ \\
\hline Score 3 & $14(29.2)$ \\
\hline \multicolumn{2}{|l|}{ ESSDAI, n (\%) } \\
\hline ESSDAI < 5 (low-activity) & $22(45.8)$ \\
\hline$\leq 5$ ESSDAI $\leq 13$ (moderate-activity) ESSDAI $\geq$ & $17(35.4)$ \\
\hline 14 (high-activity) & $9(18.8)$ \\
\hline
\end{tabular}

The correlation between ESSDAI-scores and SGUS-scores was $r=0.153(p=0.299)$. The correlation between ESSDAl-scores and ESSPRI-scores (dryness, fatique, pain) was $r=$ $0.071(p=0.632), r=0.254(p=0.082)$ and $r=-0.002(p=0.987)$. The correlation between SGUS-scores and ESSPRI-scores (dryness, fatique, pain) was $r=0.124(p=0.400), r=$ $-0.292(p=0.044)$ and $r=-0.459(p=0.001)$.

Conclusion: In a Danish cohort of SS most patients had SSa and ANA autoantibodies. SGUS demonstrated high damage (score 2-3) in approximately half of the patients. ESSDAl activity score did not correlate with SGUS damage scores or the ESSPRI. SGUS damage scores correlated with ESSPRI-scores of fatique and pain, but not dryness.

Associations between other factors of importance for damage and SGUS scores are to be analyzed. SGUS and the ESSPRI describe different SS-related dimensions and will probably contribute in disease monitoring in the future.

References:

[1] Jousse-Joulin S, D'Agostino MA, Nicolas C, Naredo E, Ohrndorf S, Backhaus $M$, et al. Video clip assessment of a salivary gland ultrasound scoring system in Sjogren's syndrome using consensual definitions: an OMERACT ultrasound working group reliability exercise. Annals of the rheumatic diseases. 2019;78(7):967-73.

Disclosure of Interests: None declared

DOI: 10.1136/annrheumdis-2020-eular.4411

\section{\begin{tabular}{|l|l}
\hline SAT0234 SERUM AXL, FERRITIN, IGFBP4 AND STNFR2 AS \\
\hline
\end{tabular} BIOMARKERS OF PEDIATRIC SLE}

S. Soliman ${ }^{1,2}$, A. Haque ${ }^{2}$, S. Mason ${ }^{3}$, L. Greenbaum ${ }^{4}$, M. J. Hicks ${ }^{5}$, C. Mohan ${ }^{2}$, S. Wenderfer ${ }^{5} .{ }^{1}$ Faculty of Medicine, Minia University, Rheumatology, Minia, Egypt; ${ }^{2}$ University of Houston, Biomedical Engineering, Houston, United States of America; ${ }^{3}$ Connecticut Children's Medical Center, Connecticut, United States of America; ${ }^{4}$ Emory University, Atlanta, United States of America; ${ }^{5}$ Texas Children's Hospital, Baylor College of Medicine, Houston, United States of America

Background: Proteomic screening is an efficient approach for identifying protein biomarkers in various inflammatory diseases. Our preliminary proteomic analysis revealed elevated levels of serum AxI, Ferritin, IGFBP4 and STNFR2 in adult patients with active lupus nephritis (LN) (1). However, the role of these serum biomarkers in pediatric systemic lupus erythematosus (SLE) patients has not been examined.

Objectives: To evaluate the performance of 4 serum protein markers for detecting disease activity in pediatric patients with SLE.

Methods: 83 pediatric patients who fulfilled $\geq 4$ ACR criteria for SLE and 25 healthy controls were recruited for serological testing of 4 protein markers identified by antibody-coated microarray screen, namely Axl, ferritin, IGFBP4 and sTNFR2. SLE disease activity was assessed using the SLEDAI-2k score, renal disease activity was assessed by the renal SLEDAI (range 0-16; $0=$ inactive LN, $\geq$ $8=$ active renal). 57 patients had clinically active SLE (SLEDAI score $\geq 4$ or having a flare) (28 active renal and 29 active non-renal SLE patients). In active renal 